\title{
AGRICULTURA URBANA COMO PRÁTICA ALTERNATIVA PARA EDUCAÇÃO AMBIENTAL: UMA PROPOSTA DE SISTEMATIZAÇÃO E AÇÕES EM SÃO LUÍS (MA)
}

\author{
Jairo Fernando Pereira Linhares ${ }^{1}$ \\ Mariano Oscar Aníbal Ibañez Rojas² \\ Maria Ivanilde de Araujo Rodrigues ${ }^{3}$
}

Resumo: Este trabalho teve como temática a sistematização de projeto de agricultura urbana (AU) como prática alternativa para a educação ambiental (EA) desenvolvido no período de 2005-2006, envolvendo uma instituição filantrópica que buscava ações para a manutenção de suas atividades, o projeto contou com a participação ativa de jovens moradores da instituição e de funcionários. Nesse sentido a implantação da horta, encontrou-se pautada na construção de oportunidades de informações, destacando-se: o aproveitamento de resíduos sólidos e ações de garantia de segurança alimentar. O uso da AU como instrumento de EA funciona como pano de fundo para discussões referentes à geração de resíduos sólidos, hortas urbanas, segurança alimentar.

Palavras-chave: Agricultura Urbana; 3Rs; Segurança Alimentar.

1 Pesquisador independente. E-mail: jairoivini29@yahoo.com.br.

2 Instituto Federal de Educação, Ciência e Tecnologia do Maranhão. E-mail: ibanez@ifma.edu.br

3 Universidade Estadual do Maranhão. E-mail: miar29@gmail.com. 


\section{Introdução}

A agricultura urbana refere-se a pequenas superfícies situadas dentro de uma cidade e destinadas à produção de cultivos e criação de pequenos animais para consumo próprio ou para a venda em mercados locais (FAO, 1999, apud MACHADO 2000).

Segundo Medeiros et al (2015) no Brasil, exemplos da disseminação da agricultura urbana podem ser vistos em Belém (PA) e São Luís (MA), onde são produzidos alimentos e espécies vegetais para fins medicinais. Na América Latina, a agricultura urbana está presente em países como Peru; México; Cuba; Costa Rica; Argentina e Uruguai.

O principal aspecto no qual a agricultura urbana difere da rural é o ambiente. A agricultura urbana pode ser realizada em qualquer ambiente urbano ou periurbano, podendo ser praticada diretamente no solo, em canteiros suspensos, em vasos, ou onde a criatividade sugerir (ROESE, 2007, p.1).

A instalação de hortas para o desenvolvimento de práticas em educação ambiental em ambiente escolar são práticas relativamente comuns, as hortaliças são plantas de ciclo curto, portanto, todo o ciclo de desenvolvimento da planta, do plantio a colheita, pode ser acompanhado pelos estudantes durante o período escolar, e as práticas pedagógicas de educação ambiental podem ser desenvolvidas repetidas vezes, durante 0 ano. A aquisição de sementes e demais insumos é outro fator que facilita a sua prática nas zonas urbanas. Por outro lado, conhecer as características da produção de hortaliças com vistas à produção para o autoconsumo em meio ambiente urbano e aproveitar esse espaço para capacitação em prol da segurança alimentar e da intervenção responsável do meio ambiente, não é uma prática corriqueira.

O objetivo do presente trabalho foi a sistematização do projeto de agricultura urbana como prática de educação ambiental, desenvolvido no período de 2005-2006 em São Luís (MA).

\section{Antecedentes a implantação do projeto}

O projeto foi desenvolvido a partir de uma ação voluntária no Lar Pouso da Esperança (Instituição filantrópica), no período de 01 ano (2005-2006), localizado em São Luís-Maranhão, doravante chamado de "Pouso". Dentre várias ações que realizava na época da implantação do projeto, estava o abrigo de um grupo de jovens mantidos através de doações. Na ocasião, o Pouso estava empenhado em buscar alternativas para minimizar a dependência externa na aquisição de alimentos, e tinha recebido apoio para escavação de dois tanques para criação de peixes, porém o apoio tinha sido suspenso e o revestimento para confecção dos tanques não foi concluído. No entanto, a necessidade e a diretriz pela busca de alternativas para minimizar a dependência externa na aquisição de alimentos persistia. Além de empresas e de outros mantenedores, o Pouso também contava com o apoio de pessoas 
físicas que doavam tempo e colaboravam das formas mais variadas, dependendo das condições financeiras e habilidades.

\section{Atividades desenvolvidas pelo projeto}

\section{Caracterização da área de trabalho}

O Pouso faz parte da área de drenagem da bacia do Rio Anil, uma das bacias mais antropizadas e povoadas de São Luís, construído numa área de topografia irregular, medindo aproximadamente $4.000 \mathrm{~m}^{2}$. Contando com uma infraestrutura dotada por um setor residencial (onde estão situados as casa lares onde os jovens residem, além de outras instalações); setor de serviços (cozinha central, lavanderia, almoxarifado, refeitório); centro de vivência; setor administrativo, e por último os setores produtivos e de apoio (onde foi desenvolvido o projeto), composto por 04 açudes para criação de peixes (em construção), sendo que o primeiro açude construído (na ocasião, encontravase desativado) já havia realizado algumas despescas de tilápias, 01 aviário para criação de patos e 01 marcenaria. O restante da área era formado por um bosque situado na parte baixa do terreno, com algumas frutíferas plantadas e uma variedade de plantas espontâneas; em parte do terreno havia uma grota inapropriada a qualquer atividade produtiva e destinada à formação de uma área de proteção permanente; o espaço destinado à instalação da horta, situado numa área de solo argiloso estava contaminado pela infiltração de uma fossa sanitária.

\section{Concepção didático-pedagógica do projeto da horta urbana}

O desenvolvimento do projeto contou com a participação dos jovens atendidos pelo Pouso e de dois funcionários da entidade. Nesse sentido a implantação da horta, foi pautada na construção de oportunidades de geração de informações que privilegiou a participação dos jovens, obedecendo às formas de convívio e de organização estabelecidas pela instituição.

Dentre as oportunidades de geração de informações, que foram priorizadas no desenvolvimento do projeto, destacaram-se: o aproveitamento de resíduos sólidos, a implantação da unidade de experimentação participativa (na formação da horta propriamente dita), ações de garantia de segurança alimentar e o emprego de técnicas agroecológicas.

Configurando desta forma, a partir da experiência vivida, num instrumento metodológico a ser desenvolvido para a prática da educação ambiental em atividades relacionadas à agricultura urbana. 


\section{Concepção do projeto de instalação da horta - "visita técnica"}

Foram realizadas medições no terreno disponível à instalação da horta, que correspondeu a uma dimensão de $20 \mathrm{~m} \times 10 \mathrm{~m}$, perfazendo $200 \mathrm{~m}^{2}$, e verificada as condições restritivas para a produção de hortaliças (solo muito argiloso e de difícil drenagem), além do solo ter sido contaminado com o vazamento de fossa sanitária da própria instituição. Complementarmente foi verificado junto aos funcionários do Pouso o histórico de uso da área, e tomouse conhecimento de um projeto anterior de produção de hortaliças desenvolvido pela instituição, e com relato de terem obtido uma pequena produção, abaixo das expectativas, principalmente no período chuvoso. Perguntados como eram produzidas as mudas de hortaliças, responderam que a produção de mudas se dava em sementeiras instaladas no próprio chão e que a "infestação de mato" era muito intensa, prejudicando a produção de mudas. Informaram também que haviam recebido como doação, uma grande quantidade de pallets (estrados de madeira usados como suporte de mercadorias), de uma empresa de produtos agropecuários, e que a empresa vendia esses pallets a baixo custo, mas mesmo assim havia acúmulo de pallets no pátio da empresa, causando problemas de falta de espaço para estocagem.

Foi perguntado aos funcionários e ao diretor do "Pouso", sobre qual a preferência de hortaliças a serem produzidas, e informaram o seguinte: alface, berinjela, beterraba, cebolinha, cenoura, coentro, couve, pimentão, repolho e tomate.

\section{Confecção e preparo dos jiraus - canteiros suspensos}

De posse das informações obtidas na visita técnica, decidiu-se pelo cultivo em "jiraus" (canteiros suspensos, muito utilizados pelos ribeirinhos na região amazônica) utilizando os pallets (estrado de madeira confeccionado para suporte de mercadorias). Outro fator que contribuiu para a adoção desse sistema foi a existência de 01 marcenaria no próprio Pouso, que foi utilizada para desmanche dos pallets e confecção dos jiraus. A seguir, os jiraus montados e instalados na área de cultivo (Figura 1.). 


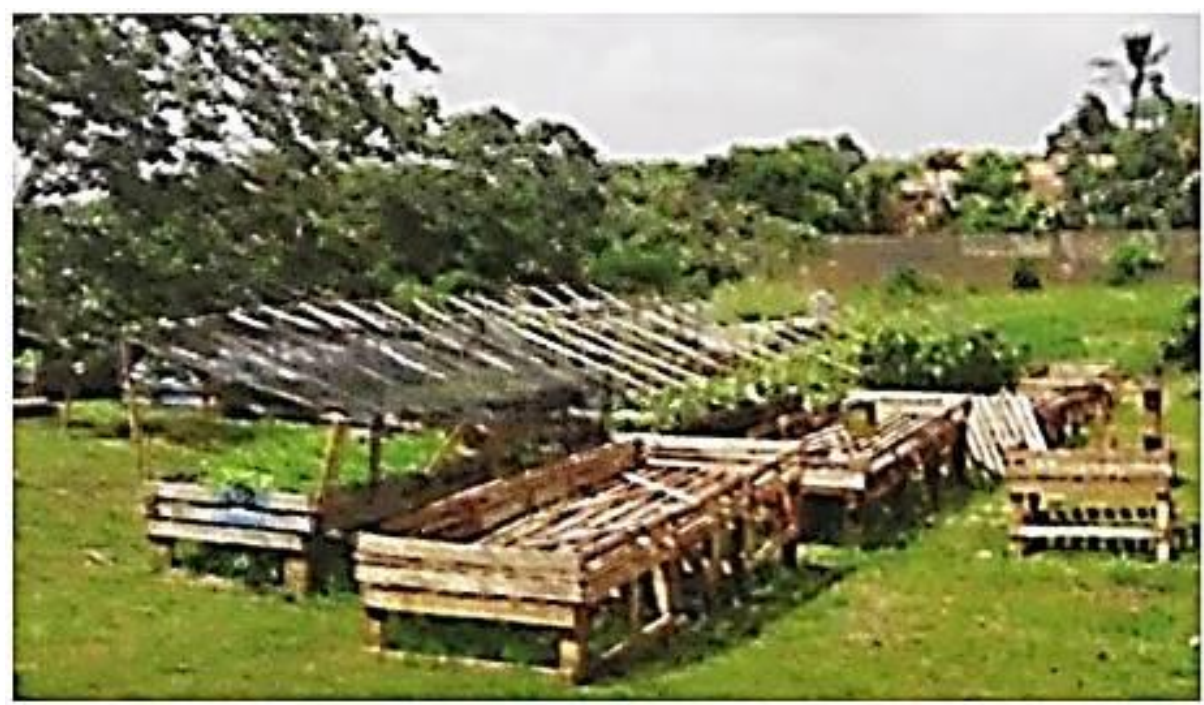

Figura 1. Jiraus numerados para plantio de hortaliças (foto: Hélio dos Santos Júnior).

As dimensões estabelecidas para a confecção dos jiraus foram: $3,0 \mathrm{~m}$ $\times 1,20 \mathrm{~m} \times 0,20 \mathrm{~m}$, definidas seguindo alguns critérios: o peso que receberá quando estiver cheio com subsolo, a largura levou-se em consideração o comprimento dos braços das pessoas que farão o manejo da horta, e a profundidade dos jiraus em $0,20 \mathrm{~m}$, foi devido a grande parte das raízes das hortaliças não chegarem a essa profundidade.

Os pallets eram confeccionados com sobras de madeiras de diferentes densidades. As partes dos pallets originárias de madeira mais dura eram colocadas na base do jirau, onde eram impermeabilizadas para aumentar a durabilidade da estrutura.

Dentro dessa perspectiva de inserção da educação ambiental neste projeto, a etapa de desmanche de pallets para confeccionar os jiraus, foi muito importante trazendo o princípio dos 3Rs (Reduzir, Reutilizar e Reciclar), onde os participantes puderam colocar em prática a reutilização de materiais como reuso de pregos e madeiras, mostrando dessa forma como economizar os recursos naturais.

Os jiraus antes de receberem o substrato para o cultivo das hortaliças foram revestidos com sacos de rafe para evitar perdas de substrato durante a irrigação, e depois de prontos foram numerados para posterior acompanhamento do histórico de plantio e também no controle e manejo de pragas e doenças das hortaliças.

Ao todo, foram confeccionados 22 jiraus, levando-se em consideração o tamanho da área disponível e os espaços entre eles, suficientes para o deslocamento de pessoas, carros-de-mão, etc. 


\section{Produção das mudas de hortaliças}

Foi adotada a produção de mudas em bandejas (Figura 2), e para isso utilizou-se como substrato a seguinte composição: húmus de minhoca, areia e vermiculita (MINAMI, 1995 p.95.). As primeiras produções de mudas foram feitas pela coordenação do projeto a título de "aprendizado".

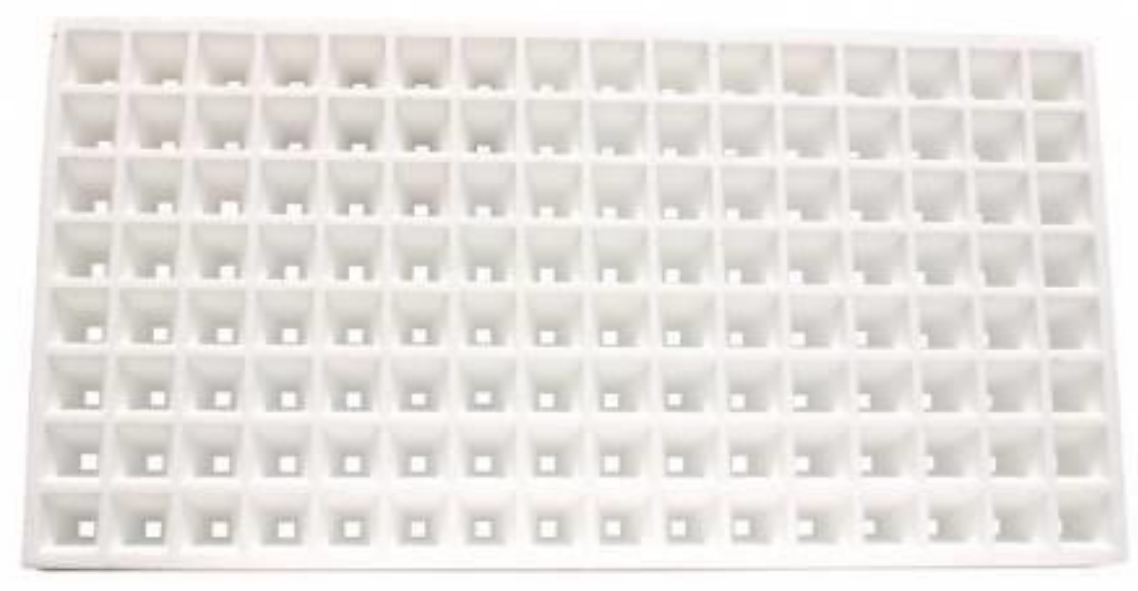

Figura 2: Bandeja de isopor para preparo de mudas de hortaliças.

Fonte: http://www.hidrosolo.net.br

Tomou-se o cuidado de explicar as razões de se adotar à produção em bandejas e a importância da adequada composição do substrato e de sua proporção para o sucesso na produção das mudas. A partir daí, os próprios jovens e funcionários do Pouso começaram a se responsabilizar pela produção das mudas. Foram utilizados dois tamanhos de bandejas, uma com 288 células de $47 \mathrm{~mm}$, para o cultivo de alface, couve, couve-flor, repolho, e outra com 128 células de $60 \mathrm{~mm}$, para o cultivo de pimenta, berinjela, repolho, pimentão, tomate.

A irrigação das bandejas foi feita com a utilização de borrifadores manuais. Após cada transplante das mudas para os jiraus, as bandejas eram lavadas com uma solução de água sanitária para prevenir o chamado "damping off" (tombamento) das mudas, causados pelo surgimento de fungos fitopatogênicos (causadores de doenças às mudas).

A produção de mudas em bandejas trouxe resultados animadores para a produção de hortaliças no Pouso, uma vez que a produção de mudas era um dos pontos de estrangulamento do cultivo de hortaliças desenvolvido anteriormente. 


\section{Manejo e condução da horta urbana}

Em virtude do conhecimento dos riscos potenciais que a agricultura praticada em área urbana pode oferecer à saúde das pessoas e ao meio ambiente, optou-se pelos princípios agroecológicos e controles alternativos de pragas, dispensando o uso de agrotóxicos.

Devido o solo estar contaminado por infiltração de esgoto, o solo utilizado na horta foi proveniente de outra localidade, adquirido através da doação de um voluntário, a partir daí o substrato para preenchimento dos canteiros, consistiu numa mistura com esterco de galinha, na proporção de 3 $\mathrm{kg}$ de esterco de galinha para cada $1 \mathrm{~m}^{2}$ de solo de canteiro suspenso (jirau).

Após a produção das mudas em bandejas (onde o tempo de produção varia em função do tipo de hortaliça), as mudas eram transplantadas para os jiraus. O espaçamento dos cultivos era definido para cada tipo de hortaliça, obedecendo às recomendações do fabricante contidas nas embalagens das sementes.

O sistema de cultivo em canteiros suspensos seguiu o modelo de agricultura urbana desenvolvido em Cuba, dentre os quais, os chamados cultivos "organopônicos", que consiste num sistema fechado de produção de hortaliças e condimentos sem vinculação direta com o solo (MINAG 2000, apud AQUINO, 2002, p.13).

Os jiraus foram adaptados com uma estrutura semelhante a uma casa de vegetação, recobertos inicialmente com um filme plástico transparente para proteger os cultivos no período chuvoso, depois foram sendo substituídas por telas de sombreamento a $20 \%$, que apesar de serem mais caras, possuem maior durabilidade e proporcionam melhores condições no desenvolvimento das hortaliças, principalmente das hortaliças folhosas. A seguir, imagem de tela de sombreamento sobre o plantio de alface (Figura 3).

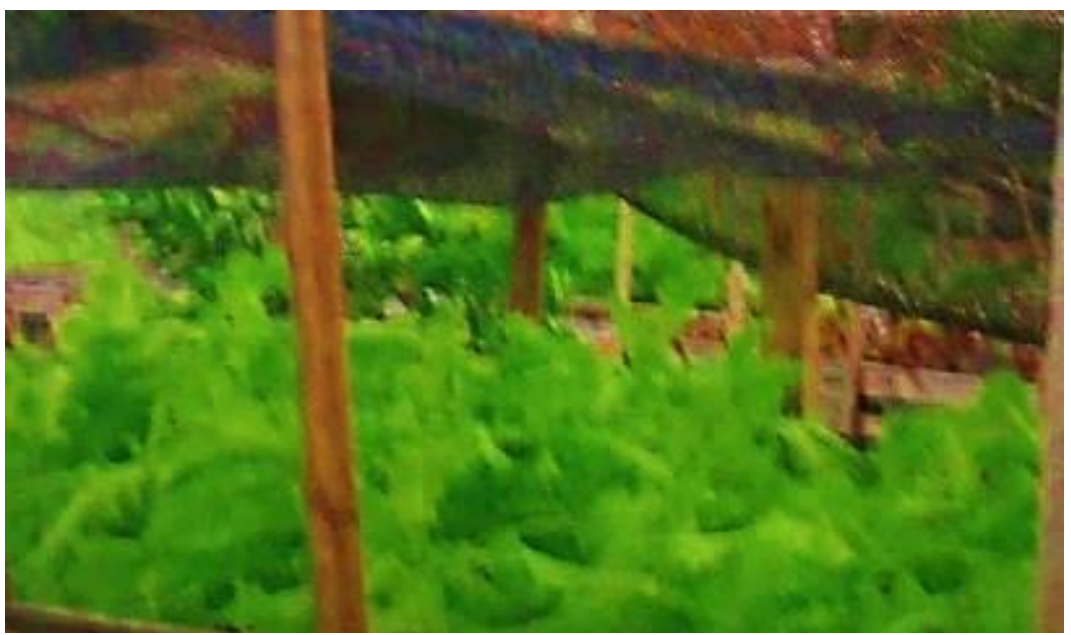

Figura 3: Jirau com alfaces coberto com tela de sombreamento

Foto: Hélio dos Santos Júnior (2005). 
Os espaçamentos utilizados para cada tipo de hortaliça (Figuras $4 \mathrm{~A} \mathrm{e}$ 4B) seguiam as recomendações existentes nas embalagens dos rótulos.

Para o manejo de pragas e doenças ${ }^{4}$, e que na vivência prática do projeto, obedeceu a uma rotação de cultivos entre os jiraus, com o objetivo de quebrar os ciclos de patógenos no substrato (mistura de solo com esterco), isto é, controlando pragas e doenças, além de economia de nutrientes da horta, desta forma, os jiraus, foram numerados para não haverem cultivos de uma mesma família de hortaliças seguidamente. Assim, foi criada uma tabela com a relação de hortaliças e suas respectivas famílias botânicas.

Outra prática adotada foi distanciar os cultivos pertencentes a uma mesma família de hortaliças, para evitar a proximidade e riscos de disseminação de patógenos.

Independente da prática de rotação de cultivos, os plantios foram atacados por insetos, principalmente pela "paquinha" (Neocurtilha hexadactila Orthoptera; Gryllotalpidae), que ataca a raiz das mudas, acarretando a perda de mudas, que eram controladas por catação manual dos insetos no substrato. A seguir, imagens dessa prática (4C e 4D).

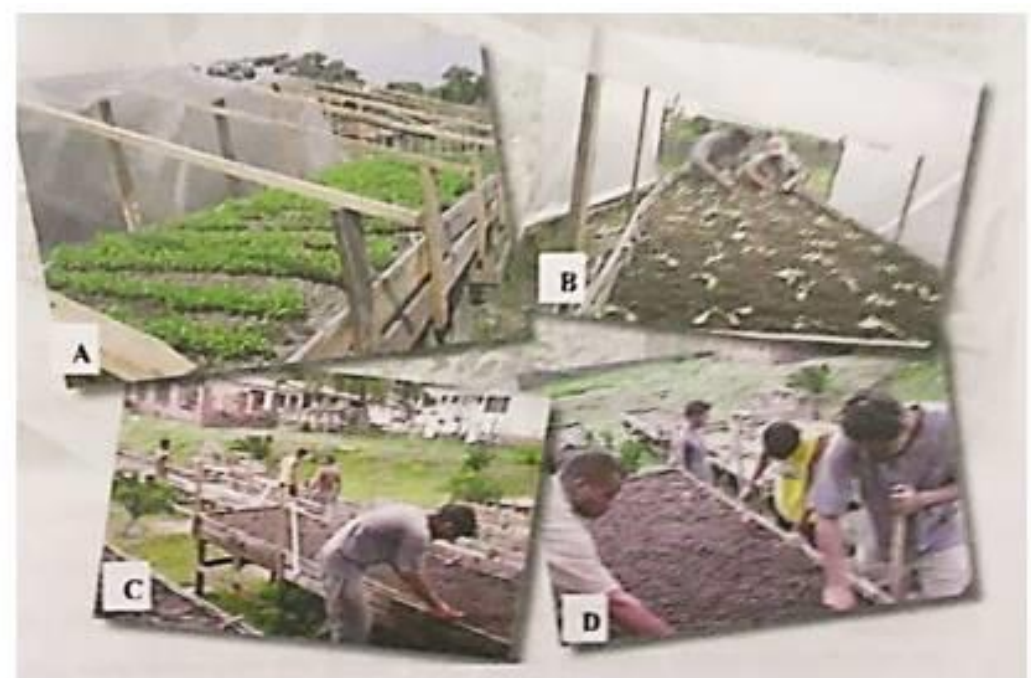

Figura 4. Jiraus com cultivo protegido ( $A$ e B) e catação de pragas do solo (C e D) (fonte: Boletim informativo do Lar Pouso da Esperança, $n^{\circ} .6$ 2005)

Com a adoção do método de catação, dispensou-se o uso de qualquer tipo de produto químico para controle de insetos no substrato, para tanto foram necessárias observações diárias e meticulosas nos substratos dos jiraus, para identificar e eliminar prontamente os insetos. Outra medida adotada para

\footnotetext{
${ }^{4}$ Este termo foi devidamente tratado com os integrantes do projeto, como uma prática adotada para manter o controle populacional de organismos que se reproduzem muito rapidamente e que pelo desequilíbrio do ambiente causado pelo ser humano, se não controlado, pode levar a perdas totais na produção agrícola.
} 
controle dos insetos no substrato foi o emprego da solarização (revolvimento do substrato para exposição dos insetos do solo).

Além do controle das paquinhas, as formigas também foram controladas, adotando o emprego de graxa na base dos jiraus, impedindo dessa forma o acesso delas aos jiraus.

A cada colheita das hortaliças, eram feitas adubações de reposição utilizando-se esterco de pato curtido (produzido no próprio Pouso) na proporção de $3 \mathrm{~kg}$ para $1 \mathrm{~m}^{2}$ de jirau, e acrescido $100 \mathrm{~g}$ de calcário dolomítico por $\mathrm{m}^{2}$ de jirau, para reposição de cálcio e magnésio.

As folhas secas das árvores existentes no Pouso, anteriormente varridas, e descartadas, passaram a ser queimadas e suas cinzas recolhidas e aplicadas, sobretudo nos tomateiros para fornecimento de potássio, que no período de floração e frutificação requer esse nutriente em maiores quantidades.

Outro manejo adotado na condução da horta, era a retirada de todas as folhas que caiam sobre o jirau, evitando assim, disseminação de doenças de uma planta provavelmente doente para as outras saudáveis. Estas folhas recolhidas eram fornecidas como alimento aos patos, que forneciam esterco para nutrição das hortaliças. Outro manejo adotado na condução da horta, era a retirada de todas as folhas que caiam sobre o jirau, evitando assim, disseminação de doenças de uma planta provavelmente doente para as outras saudáveis. Estas folhas recolhidas eram fornecidas como alimento aos patos do Pouso, que forneciam esterco para nutrição das hortaliças.

Em relação à irrigação da horta, adotamos irrigá-la nas horas mais frescas do dia (manhã e final da tarde), como forma de economia no consumo de água.

\section{Pequeno indicador da viabilidade econômica do cultivo da horta}

Foi feito um pequeno exercício sobre a relação custo/benefício do projeto, tomando como base a alface, hortaliça mais consumida pelos jovens e funcionários do Pouso. Foi levado em conta os custos necessários para a montagem de um jirau com capacidade para produzir 74 pés de alface, incluindo os custos com aquisição dos pallets (se estes tivessem sido comprados), bem como a aquisição dos insumos para a produção da alface (06 pallets, $350 \mathrm{~g}$ de prego, caixa de $250 \mathrm{~g}$ de vermiculita, 01 bandeja, pacote com $750 \mathrm{mg}$ de sementes de alface, 09 sacos de rafe, $5 \mathrm{~kg}$ de húmus, e $6 \mathrm{~m}$ de filme plástico).

Os custos na época, excluindo o valor da terra adquirida e da mão-deobra empregada, ficaram orçados em aproximadamente $\mathrm{R} \$ 90,00$ (valores da época). Comparando com os preços da alface comercializados na mesma época atingia preços médios de $R \$ 2,00$ a unidade, perfazendo assim $R \$$ 148,00 o valor a ser pago para adquirir a mesma quantidade de alfaces produzidas por cada jirau. Tirando os gastos com a implantação do jirau e os demais insumos utilizados, restaria $R \$ 58,00$ do valor a ser gasto para comprar Revbea, São Paulo, V. 13, № 1: 10-21, 2018. 
os 74 pés de alface. Sem contar que alguns insumos sobrariam para ser utilizado em outros ciclos de plantio (bandeja, húmus e vermiculita), além do próprio jirau, um pequeno indicador, mas que sinalizava para a viabilidade econômica do projeto. O que deixou o diretor, funcionários, e principalmente os jovens, motivados com os resultados alcançados.

\section{Comunicação das ações desenvolvidas - informação ambiental}

A divulgação dos resultados do projeto, em grande parte, ocorreu de forma não planejada, através das pessoas que frequentavam o Pouso, as quais acabavam conhecendo o projeto (principio e conceito adotado), e propagavam as atividades ali realizadas, inclusive despertando o interesse de outras instituições que executavam obras com objetivos semelhantes aos do "Pouso", indo verificar in loco a experiência desenvolvida.

Os boletins informativos do Pouso acabaram servindo também como veículo de divulgação dos resultados do projeto. Como pode ser observado na figura 4 do presente trabalho, extraída de um dos boletins produzidos.

Outra forma não planejada de divulgação na época ocorreu quando o diretor do Pouso criou o blog http://pousodaesperanca.zip.net, atualmente desativado, divulgando ações que o Pouso estava desenvolvendo em busca da sustentabilidade institucional. A seguir, página do blog do Pouso, com o registro fotográfico da horta (Figura 5 , próxima página).

A partir de visitas das pessoas ao projeto, das instituições que procuravam conhecer a experiência desenvolvida, e das palavras de estímulo deixadas por visitantes do blog, acabou estimulando a divulgação da experiência para outros públicos, como formadores de opinião e difusores dos conceitos, princípios e práticas da agricultura urbana, bem como, constatar a importância da AU como instrumento de EA.

Dentro dessa perspectiva, ocorreu durante a II Mostra AcadêmicoCientífica em Ciências Biológicas, da Universidade Estadual do Maranhão UEMA, o minicurso intitulado, "Agricultura Urbana: uma contribuição socioambiental", realizado no período de 09 a 13 de abril de 2007, onde foi disponibilizado as técnicas de cultivo de hortas urbanas.

Finalizando as ações de divulgação de resultados do projeto, foi elaborado como trabalho de conclusão de curso da $1^{\text {a }}$ turma de especialização em Educação Ambiental e Gestão Participativa de Recursos Hídricos, recémcriado pelo Centro Federal de Educação Tecnológica do Maranhão - CEFETMA, atualmente Instituto Federal de Educação, Ciência e Tecnologia do Maranhão - IFMA, a monografia intitulada "Agricultura urbana como prática alternativa para educação ambiental: uma proposta de sistematização e ações" (LINHARES, 2007), foi baseada nessa experiência vivenciada e que serviu de texto base para a elaboração do presente trabalho. 


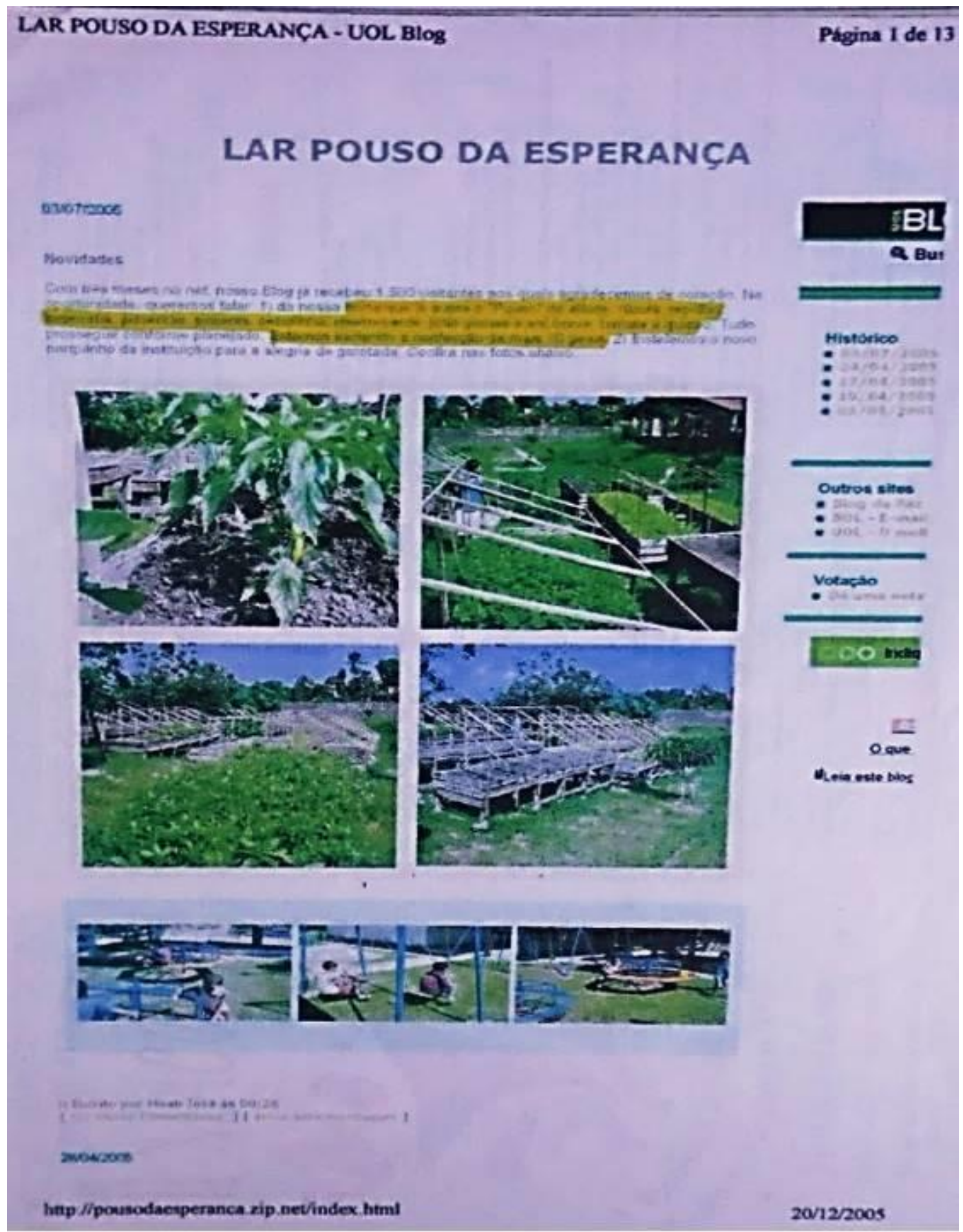

Figura 5. Página do blog Lar Pouso da Esperança. 


\section{Conclusões}

Muito embora a agricultura urbana esteja associada quase sempre a sua principal finalidade, produção de alimentos em áreas urbanas. O emprego de materiais alternativos, como o uso de resíduos sólidos, matéria orgânica, entre outros materiais que seriam descartados no ambiente, faz dessa modalidade de cultivo, uma oportunidade para quem está envolvido com a sua prática, refletir sobre questões referentes à necessidade da conservação dos recursos naturais, segurança alimentar, consumo racional de recursos hídricos, resíduos sólidos, lixo, ciclagem de nutrientes, biodiversidade, consumismo, geração de renda, bem como, outras temáticas relacionadas à sustentabilidade.

\section{Referências}

AQUINO, A. M. Agricultura Urbana em Cuba: análise de alguns aspectos técnicos. Seropédica: Embrapa Agrobiologia, 25p. Documentos, 160. 2002.

BERNA, V. Jornalismo ambiental. In: SANTOS, J.E.; SATO, M. (orgs.). A Contribuição da educação ambiental à esperança de Pandora. São Carlos: RiMa, 622p 2001, 2003, 2006.

LINHARES, J.F.P. Agricultura urbana como prática alternativa para educação ambiental: uma proposta de sistematização e ações. Monografia (Especialização Educação Ambiental e Gestão Participativa de Recursos Hídricos) - Centro Federal de Educação Tecnológica do Maranhão, 58p. 2007.

MACHADO, A.T. Agricultura urbana. Informativo do Centro Nacional de Pesquisa em Agrobiologia, no 15 - Seropédica - RJ, 2000.

MEDEIROS, G. A.; RIBEIRO, A. I.; FRACETO, L. F. L. Agricultura urbana: uma alternativa para a produção residencial de alimentos. Disponível em: http://www.jornalcruzeiro.com.br/materia/604656/agricultura-urbana-alternativapara-a-producao-residencial-de-alimentos. Acesso em: 29/03/2017.

MINAMI, K. Produção de mudas de alta qualidade em horticultura. (organizador). - T. A. Queiroz, 129p. 1995.

ROESE, A. D. Agricultura Urbana. Embrapa. Disponível em: $<$ http://www.cpap.embrapa.br> acessado em 03/04/2017. 